\title{
Do Invertors Herd: Empirical Evidence from Pakistan Stock Exchange Market and in its Major Sectors
}

\author{
Muhammad Jamil, Ghulam Ilyas, Muhammad Iqbal and Zubair Tanveer ${ }^{1}$
}

\begin{abstract}
The study is to investigate the response of stockholders about investment activities in Pakistan Stock Exchange and its major segments. Researchers have used CrossSectional Standard Deviation (CSSD) and Cross-Sectional Absolute Deviation (CSAD) approaches to evaluate herding behaviour in aforesaid market by collecting daily data on stock price from 2007 to 2014. The study finds significant evidence of the herding behaviour for the different sectors at different time in a given market. Under stress conditions of the market there are more chances that investors do herd whereas in thriving situation it has a low tendency to herd. Similarly, herding activities have different trends in bullish and bearish market conditions.
\end{abstract}

Keywords: Cross Sectional Absolute Deviation (CSAD), Cross Sectional Standard Deviation (CSSD), Herding behaviour

\section{JEL Classification: C58, G02, G11}

\section{Introduction}

Many factors in general, and choices made by others in particular, have significant impact on the decision-making process (De-Bondt, 2008). In every field of life, people are more likely to follow the experienced and the skilled individuals to minimize the uncertainty, which is known as, herding. Herd behaviour has its application in finance as Bikhchandani et al. (1996) and Devenow (1996) have stated that investors consciously follow the actions of some financial gurus. The basic rationale behind the imitation of other's actions in a financial market is to maximize the return, minimize risks and maintain a good standard in marketplace. One who provides the capital called owner, and second who manages the business called manager; and among both investment managers do herd more than the

\footnotetext{
${ }^{1}$ The authors are Assistant Professor at School of Economics, Quaid-i-Azam University, Islamabad; Senior Officer, State Bank of Pakistan; PhD Scholar, Department of Economics, University of Vienna, Austria and Staff Economist, Punjab Economic Research Institute, Lahore, respectively. Correspondent author's Email: mjamil@qau.edu.pk
} 
former with the objective to lessen the risk and keep their status standardized in the market (Stein \& Scharfstein, 1990; Trueman, 1994).

The efficient market hypothesis, which assumes investors as rational and arbitrageurs, is a traditional view of investment. Fama (1970) stated that in efficient markets prices express complete information about the markets. In contrast to the traditional view, Barberis (2003) postulated that the behavioral finance depends profoundly on the psyche of investors. Financial specialists, economists and professionals have been trying to identify the herding behaviour in stock markets for many years.

Under the herding behaviour analysis, both the adaptive and the rational expectations are used to make investment decisions. In the rational expectation method, decisions about the investment are based on investor's own analysis (Falkerenstein, 1996), whereas in adaptive expectations investors mimicked others (Bikhchandani et al., 1992). Moreover, rationality and irrationality depend upon the nature of herding, for example, if someone follows others blindly without any scientific evidence then this type of herding is known as irrational psychological behaviour whereas under the principal agent model managers rationally and intelligently follow the others to keep their standard in the market (Kenneth \& Scharfstein, 1992; Shusha \& Touny, 2016).

Moreover, the outflow of the information leads investor to make decisions based on choices of others (Banerjee, 1992; Bikhchandani et al., 1992). Another type is investigative herding where the investors analyze the feature of stocks and end up with same results (Kenneth \& Scharfstein, 1992; Hirshleifer \& Teoh, 2003). Shusha and Touny (2016) revealed that decision exactitude, hasty choice and mood of the investors were the main attitudinal determinants, but these were strongly influenced by the demographic characteristics of the investors.

For analysis purposes the present study divides the stock market into three stages based on volume of stock traded i.e. when the trade for stocks surges and market grows known as extreme higher stage or bullish trend, when stock market shrinks known as extreme lower stage or bearish trend and besides these two extremes the other is the normal market phase. For the cut-off or breaking points for extremes, Chang et al. (2000) use 5\% upper and lower values for both extremes. However, Elisabete and Marcia (2014) select both 1\% and 5\% for both extremes.

In the present section we have discussed the introduction and background of herding behaviour, the following section briefly mentions literature review and methodology of statistical estimation of data. Then in subsequent section, sample 
of the study is written by the researchers. In the closing section, the empirical results are given, and study makes conclusion in last section.

\section{Literature Review}

The study, Chang et al. (2000), found herding behaviour by employing the CSSD and CSAD for individual investors in Taiwan and South Korea. Similarly, Fotini and Nikolas (2011) analyzed herding in Portuguese, Italian, Greek and Spanish markets. Paulo and Singh (2011) investigated herding in Chinese and Indian markets using CSSD and CSAD. Further, Lin and Lin (2014) found the herding in foreign institutions and domestic institutions as well as in domestic individual investors. Riza and Kutan (2006) used CSAD method and did not find evidence of herding behaviour in Chinese stock markets. By using identical techniques (Sias, 2004; Tan \& Chiang, 2008; Bartosz \& Mark, 2013; Klein, 2013; Konstantinos \& Vasileios, 2013) provided evidence for herding behaviour at international level.

Thomas and Jiandog (2010) investigated daily data from 1996 to 2007 of Shanghai and Shenzhen stock markets with quantile regression and found that investors did herd more in first and second quantile as compare to the third. Weifeng and Cheng (2010) investigated herding behaviour in institutional funds whereas, Sias (2004) found that fund managers herded regarding mutual funds trading. In another study Rangvid et al. (2013) investigated based on panel data of 63 markets and found that the young investors herded more than the mature stockholders. However, Elisabete and Marcia (2014) identified negative relations between market sentiments and herding behaviour only in the neutral market conditions.

There are many studies that investigated the similar inquiries in the world. However, in Pakistan there is a substantial space to analyze the herding behaviour in Karachi Stock Exchange (KSEX) ${ }^{2}$ and the present study fills this gap. This research is not only a significant contribution in literature but also is valuable for financial economist, investors and practitioners in the stock market as herding actions have been attaining a substantial consideration for the last many years. Hence, we have explored the herding behaviour in different market conditions like in both extremes as well as in normal conditions with short-run and long-run

\footnotetext{
${ }^{2}$ On January 9, 2016 three stock exchange markets named Karachi Stock Exchange, Lahore Stock Exchange (LSE) and the Islamabad Stock Exchange (ISE) were merged in the Pakistan Stock Exchange (PSX). Our study used data of Karachi Stock Exchange.
} 
dynamics, consisting data from 2007 to 2014 of daily stock prices. We have also collected annual data for short run and long run analysis.

\section{Methodology}

There are many approaches used to analyze the mimicry attitude of the investors in stock markets like selling and buying of stocks, CSAD and CSSD methods applied by Sias (2004), Chang et al. (2000) and Christie \& Huang (1995) respectively. The popular method which is frequently used by the researcher is CSSD and CSAD (Chang et al., 2000; Riza \& Kutan, 2006; Tan \& Chiang, 2008; Paulo \& Singh, 2011; Tariq \& Bilal, 2013).This study applied both stated techniques to observe the presence of herding actions in Karachi Stock Exchange (KSE) as well as in its major sectors.

\subsection{Cross-Sectional Standard Deviation (CSSD)}

Christie \& Huang (1995) used CSSD to measure the linear relation between returns of individual stock and the deviation from average market returns as proposed by Treynor \& Mazuy (1966) and Black (1972), that both had proportional relationship. The Christie \& Huang (1995) constructed a formula for CSSD as:

$\operatorname{CSSD}_{t}=\sqrt{\sum_{i-1}^{N} \frac{(\text { Rit }-R m t)^{2}}{N-1}}$

Where, $\mathrm{N}$ represents total quantity of stocks, $R_{i t}$, is the returns for the stock $i$ at time $t, R_{m t}$ is average yields of the market at time $t$. Christie and Huang (1995) postulate that nonlinear or negative relationship between individual yields and average market profit indicating herding behaviour in market where the former shows less severe herding as compared to the later. They further use dummy variable for each extreme to capture the herding behaviour in stressed situations. These extreme conditions entirely depend on market structure which is different in different researches (Christie \& Huang, 1995; Chang et al., 2000; Elisabete \& Marcia, 2014). So, to include dummy for each extreme, an equation for the estimation is given as:

$\operatorname{CSSD}_{t}=\alpha+\beta^{L} D_{t}^{L}+\beta^{U} D_{t}^{U}+\varepsilon_{t}$

Where, $D_{t}^{L}$ is the dummy variable for lower extreme and $D_{t}^{U}$ is the dummy for upper extreme. These extremes are used for overall market not for individual portfolios. Statistically significant negative values of coefficient of equation (2) will prove that investors herd in specific extremes. 


\subsection{Cross-Sectional Absolute Deviation (CSAD)}

CSSD method captures the imitating activities in intense circumstances but beyond these Chang et al. (2000) claim why only in anxiety situations? The herding could be prevailed in normal situations too. Instead of using standard deviation in the equation (2) we used absolute deviation.

$\operatorname{CSSD}_{t}=\frac{1}{N} \sum_{i=1}^{N}\left|R_{i t}-R_{m t}\right|$

For both extremes Chang et al. (2000) postulate two different equations. We will capture irregular actions of the stockholders during different stock markets stages after the analysis of the general equation. Christie and Huang (1995) use 5\% and $1 \%$ as the end points to find the lower and the upper boundaries of the profit circulation.

$\operatorname{CSAD}_{t}=\gamma_{0}+\gamma_{1} R_{m t}+\gamma_{2} R_{m t}^{2}+\varepsilon_{t}$

To identify the non-linear association between separate and average market returns, the equation (4) is used; if we find the negative significant value of $\boldsymbol{\gamma}_{\mathbf{2}}$ then we may infer that herding activities prevailed in the market. By including a further $R_{m t}$ variable in equation (4), we can calculate the effects of stockholder's response in different market phases.

$C S A D_{t}=\gamma_{0}+\gamma_{1} R_{m t}+\gamma_{2}\left|R_{m t}\right|+\gamma_{3} R_{m t}^{2}+\varepsilon_{t}$

Equation (5) uses the absolute value for the asymmetry and the quadratic value for the non-linearity in mimicry attitude in the stock market. Similarly, the negative and statistically significant value of $\gamma_{3}$ indicates the non-linearity between average gain of the market and the individual return.

To detect the herding activities of the shareholders in both extremes, the study introduced a categorical variable. Zheng (2010) constructed dummy variable for each extreme presented in equation (6).

$$
\varepsilon_{t} C S A D_{t}=\gamma_{0}+\gamma_{1}(D) R_{m t}+\gamma_{2}(1-D) R_{m t}+\gamma_{3}(D) R_{m t}^{2}+\gamma_{4}(1-D) R_{m t}^{2}+
$$

In equation (6), D represents dummy variable that takes value 1 when the returns are positive and zero otherwise. The existence of herding in the lower and the upper extremes is conditional to statistically meaningful negative coefficients of $\gamma_{3}$ and $\gamma_{4}$ respectively. The CSSD is also used to identify asymmetric herd behaviour but the main objective of calculating the equation (6) is to increase consistency and to examine whether both approaches have identical outcomes or not. 


\section{Data}

The sample of 12 major sector ${ }^{3}$ of the Karachi Stock Exchange (KSEX) is selected and daily price of stocks are chosen to analyze the herding behaviour. Data is collected from Business Recorder based on their shares in the market capital ${ }^{4}$. Karachi Stock Market is major traded market of stocks in Pakistan. Due to political instability, KSEX faced many ups and downs during the reference period.

The trade of the stock is generally dependent upon the expected mean returns of the shares and the average market return and these averages are used to calculate CSSD and CSAD. In given study, average yields are measured by getting difference of $\log$ of daily prices of shares $\left[R_{i t}=100 \times\left\{\ln \left(P_{i t}\right)-\ln \left(P_{i t-1}\right)\right\}\right] .^{5}$ Further, CSSD is measured by using equation (1) with five percent from upper and lower values taking as extreme conditions to analyze the herding behaviour. For the purpose of investigating investor's mimicry performance in the lower and the upper extremes dummy variables are introduced as mentioned above. CSAD examines the presence of imitating performance in the normal conditions of the market as well.

\section{Empirical Results}

Christie and Huang (1995) used the equation (2) to observe the existence of herding in both extremes. Similarly, equation (5), estimated by Chang et al. (2000) Riza \& Kutan (2006), Tan \& Chiang (2008) and Tariq \& Bilal (2013) has been used to analyze the incidence of herding activities in usual situations. To analyze the time effect in annual data and the association between stock return and market returns, equation (5) can be calculated. Moreover, for bearish and bullish market conditions, equation (6) will be estimated. In subsequent sections, herding behaviour in extreme conditions, normal conditions as well as herding on annual basis are presented in the coming sections.

\subsection{Herding in Extreme Market Conditions}

Generally, stock markets show relatively higher sensitivity and volatility due to trading of stocks and equities on daily basis. This volatility and uncertainty lead investors to make decisions rationally to minimize the risks. During extreme conditions, there are more chances to follow the trend rather than to make

\footnotetext{
${ }^{3}$ The authors selected these 12 sectors due to their highest activeness, trading and capitalization as it is more likely that shareholders of these top active sectors herd to others.

${ }^{4}$ Business Recorder is the biggest financial daily in Pakistan founded in 1965.

${ }^{5}$ Detailed descriptive statistics are presented in Appendix A.
} 
individualistic decisions. So, in both bad and good situations in the market, investors try to herd. Christie and Huang (1995) found the leverage effect which postulated that the bad news has more effect on investors relative to the good news. The empirical evidence proves that in bearish market conditions investors herd more relative to bullish situations. For this we estimated equation (2) by taking given data.

Table 1: Herding Behavior in Extreme Market Conditions

\begin{tabular}{lllllc}
\hline Sector & & \multicolumn{1}{c}{$\boldsymbol{\gamma}_{\mathbf{0}}$} & \multicolumn{1}{c}{$\boldsymbol{\gamma}_{\mathbf{1}}$} & \multicolumn{1}{c}{$\boldsymbol{\gamma}_{\mathbf{2}}$} & \multicolumn{1}{c}{$\overline{\boldsymbol{R}}^{\mathbf{2}}$} \\
\hline ASEQ & Asset Equity & $3.6463^{* *}$ & -3.0569 & 6.8224 & 0.4147 \\
& & $(0.0430)$ & $(0.1781)$ & $(0.2127)$ & \\
ATMB & Automobile & $2.1801^{*}$ & -1.3472 & 10.7375 & 0.6501 \\
& & $(0.0781)$ & $(0.3195)$ & $(0.5242)$ & \\
BVRG & Beverages & $1.8098^{* *}$ & -1.7989 & 6.6503 & 0.5846 \\
& & $(0.0312)$ & $(0.1021)$ & $(0.1387)$ & \\
BNKG & Banking & $2.1286^{* *}$ & -1.5737 & 4.8551 & 0.4343 \\
& & $(0.0248)$ & $(0.1453)$ & $(0.1321)$ & \\
CHEM & Chemical & $2.7916^{* *}$ & -2.0554 & 7.1086 & 0.4998 \\
& & $(0.0309)$ & $(0.1299)$ & $(0.1756)$ & \\
CONS & Construction & $3.4660^{* *}$ & -1.7667 & 4.6108 & 0.3548 \\
& & $(0.0255)$ & $(0.1156)$ & $(0.1624)$ & \\
ELCT & Electricity & $13.3996^{*}$ & -12.147 & 153.8423 & 0.6185 \\
& & $(0.5216)$ & $(3.1648)$ & $(2.7532)$ & \\
HLTH & \multirow{2}{*}{ Health } & $1.7045^{* *}$ & $-1.7045^{*}$ & 8.1965 & 0.6541 \\
& & $(0.0387)$ & $(0.0920)$ & $(0.1480)$ & \\
KSEX & \multirow{2}{*}{ Karachi Stock Market } & $5.0566^{*}$ & $-3.0412^{*}$ & 9.6235 & 0.2926 \\
& & $(0.0721)$ & $(0.3578)$ & $(0.3600)$ & \\
OGEX & \multirow{2}{*}{ Oil \& Gas Exploration } & $1.2786^{* *}$ & $-1.1051^{*}$ & $2.2066^{*}$ & 0.3306 \\
& & $(0.0153)$ & $(0.0989)$ & $(0.0772)$ & \\
OGMR & Oil \& Gas Marketing & $1.9726^{* *}$ & $-1.5023^{*}$ & $2.2416^{*}$ & 0.3335 \\
& & $(0.0166)$ & $(0.0910)$ & $(0.0865)$ & \\
TRVL & \multirow{2}{*}{ Travelling } & $1.5783^{* *}$ & -1.5649 & 3.9955 & 0.4478 \\
& & $(0.0237)$ & $(0.1025)$ & $(0.1113)$ & \\
\hline
\end{tabular}

Source: Authors' own calculations. Moreover *,**, and *** indicate significance at $10 \%, 5 \%$, and $1 \%$ level of significance, respectively.

In Table 1, $\gamma_{0}$ represents the constant term, $\gamma_{1}$ indicates the direction and magnitude of herding behaviour in bottom extreme of a certain sector. Similarly, $\gamma_{2}$ is the parameter for herding activities in bullish market condition. We have mentioned it that the evidence for herding exclusively depends on the significance 
of the parameters as non-positive and statistically significant value of the parameter proving the existence of imitation.

On the other hand, the positive and significant or insignificant values imply no evidence of imitation activities (Christie \& Huang, 1995; Chang et al., 2000). Table 1 shows that $\gamma 1$ is negative and significant for all major sectors as well as for KSE which provides evidence for the presence of herding activities in all these sectors. On the other hand, $\gamma 2$ is non-negative and it can be stated that in the upper extreme of all the sectors investors do not herd. This outcome is like the study of

Table 2: Herding Behavior in Bearish and Bullish Market conditions

\begin{tabular}{|c|c|c|c|c|c|c|}
\hline Sector & $\gamma_{0}$ & $\gamma_{1}$ & $\gamma_{2}$ & $\gamma_{3}$ & $\gamma_{4}$ & $\bar{R}^{2}$ \\
\hline ASEQ & $\begin{array}{l}1.3062^{*} \\
(0.0535)\end{array}$ & $\begin{array}{l}1.2921 * \\
(0.0947)\end{array}$ & $\begin{array}{c}-1.1057 * \\
(0.0943)\end{array}$ & $\begin{array}{c}-0.0722 * * \\
(0.0282)\end{array}$ & $\begin{array}{c}-0.0005 * * \\
(0.0281)\end{array}$ & 0.4367 \\
\hline ATMB & $\begin{array}{l}1.0216^{*} \\
(0.0922)\end{array}$ & $\begin{array}{c}0.7465 \\
(0.2453)\end{array}$ & $\begin{array}{l}-0.7803 \\
(0.3093)\end{array}$ & $\begin{array}{l}0.1998 * \\
(0.0902)\end{array}$ & $\begin{array}{c}0.0633 \\
(0.1827)\end{array}$ & 0.3757 \\
\hline BVRG & $\begin{array}{l}1.0179 * * \\
(0.0316)\end{array}$ & $\begin{array}{l}0.7005^{*} \\
(0.0707)\end{array}$ & $\begin{array}{l}-0.6855^{*} \\
(0.0644)\end{array}$ & $\begin{array}{c}0.0549 * * \\
(0.0269)\end{array}$ & $\begin{array}{c}0.0265 * * \\
(0.0206)\end{array}$ & 0.3991 \\
\hline BNKG & $\begin{array}{c}0.4650 * * \\
(0.0477)\end{array}$ & $\begin{array}{l}0.8778^{*} \\
(0.0787)\end{array}$ & $\begin{array}{c}-0.8323 * \\
(0.0866)\end{array}$ & $\begin{array}{l}-0.0039 \\
(0.204)\end{array}$ & $\begin{array}{c}0.0069 * * \\
(0.0248)\end{array}$ & 0.4157 \\
\hline CHEM & $\begin{array}{l}1.4590 * * \\
(0.0249)\end{array}$ & $\begin{array}{c}0.3586 * * \\
(0.0131)\end{array}$ & $\begin{array}{l}-0.2383^{*} \\
(0.0712)\end{array}$ & $\begin{array}{l}0.1998^{*} \\
(0.0902)\end{array}$ & $\begin{array}{c}0.2813 * * \\
(0.0264)\end{array}$ & 0.4437 \\
\hline CONS & $\begin{array}{c}2.1289 * * \\
(0.0250)\end{array}$ & $\begin{array}{c}-0.0595^{* *} \\
(0.0476)\end{array}$ & $\begin{array}{c}-0.7284 * \\
(0.0531)\end{array}$ & $\begin{array}{c}0.1401^{* *} \\
(0.0155)\end{array}$ & $\begin{array}{c}0.0243 * * \\
(0.0203)\end{array}$ & 0.4690 \\
\hline ELCT & $\begin{array}{l}1.9241 * \\
(0.0673)\end{array}$ & $\begin{array}{c}0.5289 \\
(0.1037)\end{array}$ & $\begin{array}{l}-0.8258 \\
(0.1053)\end{array}$ & $\begin{array}{c}0.1467 * * \\
(0.0290)\end{array}$ & $\begin{array}{c}0.0759 * * \\
(0.0290)\end{array}$ & 0.4138 \\
\hline HLTH & $\begin{array}{l}0.1947 * \\
(0.0610)\end{array}$ & $\begin{array}{c}1.6240 \\
(0.1122)\end{array}$ & $\begin{array}{l}-1.4555 \\
(0.1151)\end{array}$ & $\begin{array}{c}-0.1726^{* *} \\
(0.0316)\end{array}$ & $\begin{array}{c}-0.1320 * * \\
(0.0314)\end{array}$ & 0.2989 \\
\hline KSEX & $\begin{array}{l}1.8954^{* *} \\
(0.0226)\end{array}$ & $\begin{array}{c}0.4961 * \\
(0.0635)\end{array}$ & $\begin{array}{l}-0.6793^{*} \\
(0.0622)\end{array}$ & $\begin{array}{l}-0.0259^{* *} \\
(0.0274)\end{array}$ & $\begin{array}{l}-0.0459 \\
(0.232)\end{array}$ & 0.1762 \\
\hline OGEX & $\begin{array}{l}0.9601 * * \\
(0.0348)\end{array}$ & $\begin{array}{l}0.3443 * \\
(0.0732)\end{array}$ & $\begin{array}{l}-0.5451 * \\
(0.0871)\end{array}$ & $\begin{array}{l}0.0971 * * \\
(0.0274)\end{array}$ & $\begin{array}{l}-0.0545^{* *} \\
(0.0411)\end{array}$ & 0.1816 \\
\hline OGMR & $\begin{array}{l}1.2252 * * \\
(0.0303)\end{array}$ & $\begin{array}{l}0.0768 * \\
(0.0654)\end{array}$ & $\begin{array}{l}-0.4256^{*} \\
(0.0800)\end{array}$ & $\begin{array}{l}0.1956^{* *} \\
(0.0256)\end{array}$ & $\begin{array}{l}-0.0256^{* *} \\
(0.0398)\end{array}$ & 0.1909 \\
\hline TRVL & $\begin{array}{l}0.4605 * * \\
(0.0330)\end{array}$ & $\begin{array}{l}1.0160^{*} \\
(0.0634)\end{array}$ & $\begin{array}{l}-1.0487 * \\
(0.0643)\end{array}$ & $\begin{array}{l}-0.0598^{* *} \\
(0.0200)\end{array}$ & $\begin{array}{l}-0.1203^{* *} \\
(0.0214)\end{array}$ & 0.4087 \\
\hline
\end{tabular}

Source: Authors' own calculations. Moreover *,**, and *** indicate Significance at $10 \%, 5 \%$, and $1 \%$ level of significance, respectively.

Christie and Huang (1995). The equation (5) contains the nominal variables for lower and upper extremes. Christie and Huang (1995) take 5\% values as upper and 
lower extreme and Zheng (2010) takes negative and positive values as the lower and upper extremes situations, respectively. The results of equation (5) are shown in Table 2.

The intercept is $\gamma_{0}, \gamma_{1}$ is the coefficient for upper extreme and $\gamma_{2}$ is the parameter for lower extreme. From the results of Table 2, it can be found that coefficient $\gamma_{3}$ is negative significant for health, asset and equity and travelling sector which reveals that in these sectors investors herd in the upper extreme of market, however $\gamma_{4}$ is revealed herding actions of stockholders in the lower extreme of KSE, health and travelling sectors. From above two equations [ $2 \& 5$ ], we found diverse results. From the equation we have found that lower extreme has herding behaviour but in the other equation both the lower and the upper extremes have imitation activities in different sectors. The results are aligned with (Chang et al., 2000; Christie \& Huang, 1995) that during anxiety stockholders try to herd.

\subsection{Herding in Normal Market Conditions}

Our study has used a method to scrutinize the presence of imitating activities in KSE in its major sectors during the regular market conditions proposed by Chang et al. (2000). The results in Table 3 are calculated after the estimation of the equation (5) showing the association of market and individual returns.

From Table 3, the values of the parameter $\gamma_{3}$ are not only negative but also statistically significant for Asset \& Equity, Health sectors, travelling and KSE which shows that these sectors have non-linear association of their specific return and market return, hence, indicates the existence of the herding attitude in these sectors. The estimated parameter is significant at $10 \%$ probability.

Table 3: Results of Herding Behaviour in Normal Market situations

\begin{tabular}{lccccc}
\hline Sector & $\gamma_{\mathbf{0}}$ & $\boldsymbol{\gamma}_{\mathbf{1}}$ & $\boldsymbol{\gamma}_{\mathbf{2}}$ & $\boldsymbol{\gamma}_{\mathbf{3}}$ & $\overline{\boldsymbol{R}}^{\mathbf{2}}$ \\
\hline ASEQ & $1.3086^{*}$ & $-0.0001^{* *}$ & $1.1983^{*}$ & $-0.0361^{* *}$ & 0.4356 \\
& $(0.0535)$ & $(0.0185)$ & $(0.0816)$ & $(0.0225)$ & \\
ATMB & $1.0430^{*}$ & $0.0778^{*}$ & 0.6780 & $0.1845^{*}$ & 0.3768 \\
& $(0.0877)$ & $(0.0667)$ & $(0.2121)$ & $(0.0878)$ & \\
BVRG & $1.0148^{* *}$ & $0.0370^{* *}$ & $0.7034^{*}$ & $0.0357^{* *}$ & 0.3991 \\
& $(0.0316)$ & $(0.0155)$ & $(0.0574)$ & $(0.0182)$ & \\
BNKG & $0.4639^{* *}$ & $0.0067^{* *}$ & $0.8588^{*}$ & $0.0001^{* *}$ & 0.4160 \\
& $(0.0477)$ & $(0.0164)$ & $(0.0692)$ & $(0.0175)$ & \\
CHEM & $1.1836^{* *}$ & $0.0209^{* *}$ & $0.7895^{*}$ & $0.1248^{* *}$ & 0.4805 \\
& $(0.0331)$ & $(0.0193)$ & $(0.0648)$ & $(0.0209)$ & \\
CONS & $2.1427^{* *}$ & $-0.2758^{* *}$ & $0.2914 * *$ & $0.1022^{* *}$ & 0.4618 \\
\hline
\end{tabular}




\begin{tabular}{lccccc}
\hline & $(0.0250)$ & $(0.0114)$ & $(0.0431)$ & $(0.0138)$ & \\
ELCT & $1.9241^{*}$ & $-0.0488^{* *}$ & $0.6715^{*}$ & $0.1135^{* *}$ & 0.4128 \\
& $(0.0673)$ & $(0.0194)$ & $(0.0914)$ & $(0.0229)$ & \\
HLTH & $0.1967 *$ & $0.0249^{* *}$ & $1.5413^{*}$ & $-0.1522^{* *}$ & 0.2989 \\
& $(0.0610)$ & $(0.0262)$ & $(0.0934)$ & $(0.0242)$ & \\
KSEX & $1.8954 * *$ & $-0.0746^{* *}$ & $0.5904^{*}$ & $-0.0380^{* *}$ & 0.1764 \\
& $(0.0225)$ & $(0.0183)$ & $(0.0535)$ & $(0.0195)$ & \\
OGEX & $0.9816^{* *}$ & $0.0291^{* *}$ & $0.3727 *$ & $0.0598^{* *}$ & 0.1768 \\
& $(0.0344)$ & $(0.0167)$ & $(0.0667)$ & $(0.0254)$ & \\
OGMR & $1.2539 * *$ & $0.0007 * *$ & $0.1437 *$ & $0.1457^{* *}$ & 0.1793 \\
& $(0.0300)$ & $(0.0158)$ & $(0.0607)$ & $(0.0240)$ & \\
TRVL & $0.4634 * *$ & $0.0538^{* *}$ & $1.0280^{*}$ & $-0.0874 * *$ & 0.4073 \\
& $(0.0330)$ & $(0.0145)$ & $(0.0547)$ & $(0.0163)$ & \\
\hline
\end{tabular}

Source: Authors' own calculations. Moreover *,**, and *** indicate Significance at 10\%, 5\%, and $1 \%$ level of significance, respectively.

\subsection{Estimation of Herding Behaviour on Annual Basis}

We have analyzed the daily data so far for herding behaviour. The length of data is from 2007 to 2014 and throughout this period Pakistan had been facing some political and economic uncertainties like murder of Mohtarma Benazir Bhutto, financial crisis of 2008, changes in political settlement from Musharraf to the Pakistan People's Party (PPP), and from the PPP to the Pakistan Muslim LeagueNawaz (PML-N) and fight against terrorism. To find out the impact of these activities in general, and herding behaviour in particular in the KSE, the study tries to investigate the data annually. The table 4 shows the results of the equation (5) using annual data of given sample.

Oil \& Gas sector has evidence for herding only in 2007, and in 2008 health sector shows herding activities whereas automobiles sector exhibit mimicry in 2009. Moreover, travelling sector of KSE has an indication of imitating activities during year 2007, 2009, 2010 and 2014. KSE has strong herding indication for 2012 but week evidence during 2009-11 due to insignificant negative value of respected coefficient.

It can be verified that the herding activities exist in the inferior extreme as also proved by (Christie \& Huang, 1995; Chang et al., 2000). Similarly, Zheng (2010) method demonstrates that health and travelling sector as well as the KSE have empirical signs of herding in the bottom extreme however, the Asset and Equity sector is showing imitation in the higher extreme of market. 
Table 4: Results of Annual Data in Normal Market Condition

\begin{tabular}{|c|c|c|c|c|c|c|c|c|c|}
\hline \multirow{2}{*}{ Sectors } & 2007 & 2008 & 2009 & 2010 & 2011 & 2012 & 2013 & 2014 & 2007-14 \\
\hline & $\gamma_{3}$ & $\gamma_{3}$ & $\gamma_{3}$ & $\gamma_{3}$ & $\gamma_{3}$ & $\gamma_{3}$ & $\gamma_{3}$ & $\gamma_{3}$ & $\gamma_{3}$ \\
\hline \multirow{2}{*}{ ASTNEQT } & $0.1643 *$ & $0.0922 *$ & $-0.2178 *$ & $-0.0996^{*}$ & $0.1257^{*}$ & $0.0510 *$ & $-0.0079 * *$ & $0.1080 *$ & $-0.0361 * *$ \\
\hline & $(0.0531)$ & $(0.0631)$ & $(0.0587)$ & $(0.0645)$ & $(0.0798)$ & $(0.0829)$ & $(0.0462)$ & $(0.0807)$ & $(0.0225)$ \\
\hline \multirow{2}{*}{ ATMB } & $0.1580 *$ & $0.3852 *$ & -0.5460 & $0.0603 * *$ & $0.3404 *$ & $0.1944 * *$ & $-0.0789 *$ & $0.1585^{*}$ & $0.1845^{*}$ \\
\hline & $(0.0546)$ & $(0.0915)$ & $(0.1081)$ & $(0.0428)$ & $(0.0578)$ & $(0.0377)$ & $(0.0673)$ & $(0.0564)$ & $(0.0878)$ \\
\hline \multirow{2}{*}{ BVRG } & $0.3546^{*}$ & $0.5010^{*}$ & $-0.0391 * *$ & $0.0549 * *$ & $0.2715^{*}$ & $0.1338^{*}$ & $0.1597 *$ & $0.0046^{*}$ & $0.0357 * *$ \\
\hline & $(0.0823)$ & $(0.0667)$ & $(0.0449)$ & $(0.0480)$ & $(0.0656)$ & $(0.0659)$ & $(0.0524)$ & $(0.0665)$ & $(0.0182)$ \\
\hline \multirow{2}{*}{ BNKG } & $-0.0191 * *$ & $0.0258 * *$ & $-0.2448^{*}$ & $-0.0606^{*}$ & $-0.0448 *$ & $0.2007 * *$ & $0.1540 * *$ & $-0.1321 * *$ & $0.0001 * *$ \\
\hline & $(0.0178)$ & $(0.0420)$ & $(0.0508)$ & $(0.0555)$ & $(0.0581)$ & $(0.0418)$ & $(0.0482)$ & $(0.0424)$ & $(0.0175)$ \\
\hline \multirow{2}{*}{ CHEM } & $0.0238 * *$ & $0.2315^{*}$ & $-0.0402 *$ & $0.1125^{*}$ & $0.3071 * *$ & $0.2472 *$ & 0.2607 & $0.1251 *$ & $0.1248 * *$ \\
\hline & $(0.0496)$ & $(0.0514)$ & $(0.0646)$ & $(0.0621)$ & $(0.0420)$ & $(0.0658)$ & $(0.1008)$ & $(0.0560)$ & $(0.0209)$ \\
\hline \multirow{2}{*}{ CONS } & $0.1643^{*}$ & $0.1538^{*}$ & $-0.0175^{* *}$ & $0.1243^{* *}$ & $0.0646^{* *}$ & $0.0754 * *$ & $-0.0375^{* *}$ & $0.1904 * *$ & $0.1022 * *$ \\
\hline & $(0.0531)$ & $(0.0507)$ & $(0.0411)$ & $(0.0302)$ & $(0.0454)$ & $(0.0357)$ & $(0.0411)$ & $(0.0427)$ & $(0.0138)$ \\
\hline \multirow{2}{*}{ ELECT } & $0.1580^{*}$ & $-0.0170^{*}$ & $0.1454^{*}$ & $0.2018 *$ & $0.0541 *$ & $0.1219 *$ & $-0.0247 * *$ & $0.1210 *$ & $0.1135 * *$ \\
\hline & $(0.0546)$ & $(0.0610)$ & $(0.0921)$ & $(0.0739)$ & $(0.0685)$ & $(0.0557)$ & $(0.0451)$ & $(0.0509)$ & $(0.0229)$ \\
\hline \multirow[t]{2}{*}{ HLTH } & $-0.0191 * *$ & $-0.3603^{*}$ & $-0.1574 *$ & $-0.1849^{*}$ & -0.5165 & $-0.2764 *$ & $-0.1674 *$ & -0.4165 & $-0.1522 * *$ \\
\hline & $(0.0178)$ & $(0.0940)$ & $(0.0566)$ & $(0.0628)$ & $(0.2702)$ & $(0.0646)$ & $(0.0566)$ & $(0.2702)$ & $(0.0242)$ \\
\hline \multirow[t]{2}{*}{ KSE } & $0.3546^{*}$ & 0.1253 & $-0.0063^{*}$ & $-0.0270 * *$ & $-0.0455 * *$ & $-0.1234^{*}$ & $-0.0170 * *$ & 0.4206 & $-0.0380 * *$ \\
\hline & $(0.0823)$ & $(0.1290)$ & $(0.0769)$ & $(0.0302)$ & $(0.0494)$ & $(0.0690)$ & $(0.0302)$ & $(0.1257)$ & $(0.0195)$ \\
\hline \multirow[t]{2}{*}{ ONGEX } & $-0.2011 *$ & 0.2841 & $0.1655^{*}$ & 0.0595 & $0.2968^{*}$ & $0.0312 *$ & $0.0076^{*}$ & 0.0229 & $0.0598 * *$ \\
\hline & $(0.0894)$ & $(0.1858)$ & $(0.0545)$ & $(0.1162)$ & $(0.0838)$ & $(0.0661)$ & $(0.0612)$ & $(0.1012)$ & $(0.0254)$ \\
\hline \multirow[t]{2}{*}{ ONGMRK } & $-0.0905^{*}$ & $0.3455^{*}$ & $0.3319^{*}$ & $0.0531 *$ & $-0.0446^{*}$ & $-0.0992 *$ & $-0.0206^{*}$ & $0.1869 *$ & $0.1457 * *$ \\
\hline & $(0.0547)$ & $(0.550)$ & $(0.0536)$ & $(0.0915)$ & $(0.0981)$ & $(0.0759)$ & $(0.0706)$ & $(0.0508)$ & $(0.0240)$ \\
\hline \multirow[t]{2}{*}{ TRVL } & $-0.0905^{*}$ & $-0.0613 * *$ & $-0.2211 * *$ & $-0.1298^{*}$ & $0.1015^{*}$ & $0.0021 *$ & $0.0074 *$ & $-0.0284 * *$ & $-0.0874 * *$ \\
\hline & $(0.0547)$ & $(0.0483)$ & $(0.0425)$ & $(0.0551)$ & $(0.0655)$ & $(0.0508)$ & $(0.0501)$ & $(0.0416)$ & $(0.0163)$ \\
\hline
\end{tabular}

Source: Authors' own calculations. Moreover ***, and $* * *$ indicate Significance at $10 \%, 5 \%$, and $1 \%$ level of significance, respectively. 


\section{Conclusion}

The study investigated the imitation in the KSE market and in its major sectors. For this purpose, we used the daily data of stocks from 2007 to 2014 . The estimation had three different market conditions, lower and upper extremes are two in addition to normal market conditions. For the extreme conditions CSSD is applied to examine the dispersion among individual yields and average market returns as used by Christie and Huang (1995) with dummy for both the extremes, for the bearish and the bullish market conditions. Similarly, for normal market conditions CSAD was used to identify the asymmetric behaviour of the stockholders throughout different stages of the stock markets as well as to determine the non-linear association between individual returns and market profit dispersions (Chang et al., 2000).

The estimated results based on the CSSD show the significant evidence of herding activities during bearish situations in the KSE and all of its selected sectors. This is an indication of the presence of leverage effect in the stock market. The travelling and health sectors have the herding behaviour in the upper and the lower extremes of market. The KSE has herding activities in only bearish whereas; asset \& equity has herding behaviour only upper extreme conditions. KSE itself, travelling, asset \& equity and health sectors have herding behaviour in normal conditions. Lastly, the results reveal that the imitation varies from time to time. The results of our study were similar to earlier studies (Christie \& Huang, 1995; Chang et al., 2000).

The present study has many implications for the investors by helping them in identification of risk potential in different sectors as well as it can guide them in formulating appropriate portfolio for the investment in KSE and its respective sectors in both, the normal, and the abnormal conditions in the market. The study can be extended by using daily, weekly and monthly data on other sectors of not only KSE but also of Lahore and Islamabad stock exchanges. 


\section{References}

Banerjee, A. (1992). A simple model of herd behavior, Quarterly Journal of Economics, 107(3), 797-817.

Barberis, N. \& Thaler, R. (2003). A Survey of Behavioural Finance, In Handbook of the Economics of Finance, Edited by G.M. Constantinides, M. Harris and R. Stulz.

Bartosz, G. E., \& Mark, E. W. (2013). International herding: Does it differ across sectors? International Financial Markets, Institutions and Money, 23, 5584.

Bikhchandani, S., Hirshlefir, D., \& Welch, I. (1992). A theory of fads, fashion, custom, and cultural change as informational cascades, The Journal of Political Economy, 992-1026.

Black (1972). Capital market equilibrium with restricted borrowing, Journal of Business, 45, 444-454.

Chang, E. C., Cheng, J. W., \& Khorana, A. (2000). An examination of herd behaviour in equity. Journal of Banking \& Finance, 24, 1651-1679.

Christie, W. G., \& Huang, R. D. (1995). Following the pied piper: Do individual returns herd around the market? Financial Analysts Journal, 51, 31-37.

De-Bondt, W. M. (2008). Behavioural finance Quo Vadis? Journal of Applied Finance, 18(2), 7.

Devenow, A. (1996). Rational herding in financial economics, European Economic Review, 40(3), 603-615.

Elisabete, F. S., \& Marcia, S. V. (2014). Herding behaviour and sentiment: Evidence in a small European market, Revista de Contabilidad - Spanish Accounting Review, 18(1), 78-86.

Falkerenstein, E. (1996). Preferences for stock characteristics as revealed by mutual fund portfolio holdings. Journal of Finance, 51, 111-135.

Fama, E. (1970). Efficient capital markets: A review of theory and empirical work, The Journal of Finance, 25(2), 383-417.

Fotini, E., \& Nikolas, P. (2011). Cross-country effects in herding behaviour: Evidence from four South European markets, International Financial Markets, Institutions and Money, 21, 443-460. 
Hirshleifer, D., \& Teoh, S. H. (2003). Herd behaviour and cascading in capital markets: A review and synthesis. European Financial Management, 9, 2566.

Kenneth, F. A., \& Scharfstein, D. S. (1992). Herd on the street: informational inefficiencies in a market with sort-term speculation, The Journal of Finance, 47(4), 1461-1484.

Klein, A. C. (2013). Time-variations in herding behaviour: Evidence from a Markov switching SUR model, International Financial Markets, Institutions and Money, 26, 291- 304.

Konstantinos, G., \& Vasileios, K. (2013). Institutional industry herding: Intentional or spurious? International Financial Markets, Institutions and Money, 26, 192-214.

Lin, A. Y. \& Lin, Y. (2014). Herding of institutional investors and margin traders on extreme market movements, International Review of Economics and Finance, 33, 186-198.

Paulo, L., \& Singh, H. (2011). Herding behaviour in the Chinese and Indian stock markets, Journal of Asian Economics, 22, 495-506.

Rangvid, J., Schmeling, M., \& Schrimpf, A. (2013). What do professional forecasters' stock market expectations tell us about herding, information extraction and beauty contests? Journal of Empirical Finance, 20, 109-12.

Riza, D., \& Kutan, A. M. (2006). Does herding behaviour exist in Chinese stock markets? International Financial Markets, Institutions and Money, 16, $123-142$.

Shusha, A. A., \& Touny, M. A. (2016). The attitudinal determinants of adopting the herd behaviour: an applied study on the Egyptian exchange, Journal of Finance and Investment Analysis, 5(1), 55-69

Sias, R. (2004). Institutional herding, Review of Financial Studies, 17, 165-206.

Stein, J. C., \& Scharfstein, D. S. (1990). Herd behaviour and investment, American Economic Review, 80, 465-479.

Tan, L., \& Chiang, T. C. (2008). Herding behaviour in Chinese stock markets: An examination of A and B shares, Pacific-Basin Finance Journal, 16, 61-77. 
Tariq, J., \& Bilal, H. (2013). Herding behaviour in Karachi Stock Exchange, International Journal of Management Sciences and Business Research, 2(2), 19-28

Thomas, C. C., \& Jiandog, L. (2010). Empirical investigation of herding behaviour in Chinese stock markets: Evidence from quantile regression analysis, Global Finance Journal, 21, 111-124.

Treynor, J., \& Mazuy, F. (1966). Can mutual funds outguess the market? Harvard Business Review, 44, 131-136.

Trueman, B. (1994). Analyst forecasts and herding behaviour, Review of Financial Studies, 7, 97-124.

Weifeng, H., \& Cheng, F. L. (2010). Mutual fund herding its impact on stock returns: Evidence from the Taiwan stock market, Pacific-Basin Finance Journal, 18, 477-493.

Zheng, C. T. (2010). An empirical analysis of herd behaviour in global stock markets, Journal of Banking and Finance, 34(8), 1911-1921. 


\section{Appendix A1: Descriptive Statistics of Average Return of the KSE and its Major Sectors}

\begin{tabular}{llrlllll}
\hline Sector & Obs. & Mean & MAX & MIN & St. Dev. & Skewness & Kurtosis \\
\hline ASEQ & 1945 & -0.0023 & 4.7900 & -4.9109 & 1.4497 & -0.0790 & 3.7969 \\
ATMB & 1945 & -0.0052 & 4.8269 & -4.7473 & 0.9927 & 0.0095 & 5.5314 \\
BNKG & 1945 & 0.0052 & 4.4040 & -4.8138 & 1.07996 & -0.2452 & 4.9890 \\
BVRG & 1945 & 0.1011 & 4.9608 & -4.8721 & 1.6113 & 0.1495 & 3.9290 \\
CHEM & 1945 & 0.0013 & 4.9367 & -4.7325 & 0.9606 & -0.2063 & 6.2246 \\
CONS & 1945 & -0.0039 & 4.7922 & -4.8334 & 1.6288 & -0.0141 & 3.5016 \\
ELCT & 1945 & 0.2026 & 4.8221 & -4.4551 & 1.1267 & 0.1872 & 4.3222 \\
HLTH & 1945 & -0.0127 & 4.8946 & -4.9043 & 1.4407 & -0.1103 & 4.9372 \\
KSEX & 1945 & 0.0280 & 3.8960 & -4.5453 & 0.7107 & -0.4792 & 8.7790 \\
OGEX & 1945 & -0.0422 & 4.6287 & -3.1640 & 1.0330 & 0.2804 & 3.6885 \\
OGMR & 1945 & 0.0130 & 4.4303 & -3.5288 & 0.9462 & 0.2348 & 3.8894 \\
TRVL & 1945 & -0.0033 & 4.9102 & -4.9756 & 1.2153 & 0.2127 & 4.5734 \\
\hline
\end{tabular}

Source: Author's own calculations

Appendix A2: Descriptive Statistics of Cross-Sectional Standard Deviation

\begin{tabular}{llllllll}
\hline Sector & Obs. & Mean & MAX & MIN & St.Dev. & Skewness & Kurtosis \\
\hline ASEQ & 1945 & 3.7380 & 15.082 & 0.0000 & 2.3590 & 1.2516 & 4.8739 \\
ATMB & 1945 & 2.6609 & 18.810 & 0.0000 & 2.0071 & 3.3146 & 18.461 \\
BNKG & 1945 & 2.2513 & 10.860 & 0.2719 & 1.4122 & 1.8509 & 8.0495 \\
BVRG & 1945 & 1.9566 & 14.246 & 0.0000 & 1.9895 & 2.3705 & 10.963 \\
CHEM & 1945 & 3.4905 & 9.3448 & 1.3960 & 1.3541 & 1.2895 & 5.0163 \\
CONS & 1945 & 2.8868 & 14.656 & 0.0000 & 1.8461 & 2.2298 & 9.1181 \\
ELCT & 1945 & 1.8874 & 14.481 & 0.0000 & 2.5598 & 2.0682 & 6.9532 \\
HLTH & 1945 & 5.3088 & 21.368 & 1.7141 & 3.6326 & 1.7399 & 5.3743 \\
KSEX & 1945 & 1.3381 & 8.8046 & 0.0789 & 0.8011 & 1.8389 & 13.403 \\
OGEX & 1945 & 2.0043 & 6.7542 & 0.1922 & 0.8702 & 0.5365 & 3.7121 \\
OGMR & 1945 & 1.6704 & 7.6208 & 0.0000 & 1.3418 & 1.2501 & 4.8629 \\
\hline
\end{tabular}

Source: Author's own calculations. 
Appendix A3: Descriptive Statistics of Cross-Sectional Absolute Deviation

\begin{tabular}{llllllll}
\hline Sector & Obs. & Mean & MAX & MIN & St.Dev. & Skewness & Kurtosis \\
\hline ASEQ & 1945 & 2.5235 & 9.7328 & 0.0000 & 1.5799 & 1.2250 & 4.7834 \\
ATMB & 1945 & 1.7806 & 9.6878 & 0.0000 & 1.0923 & 2.6253 & 14.202 \\
BNKG & 1945 & 1.6115 & 6.6934 & 0.2248 & 0.9406 & 1.6030 & 6.4444 \\
BVRG & 1945 & 1.4552 & 10.965 & 0.0000 & 1.5060 & 2.4884 & 11.723 \\
CHEM & 1945 & 1.8327 & 9.7713 & 0.0000 & 1.1300 & 2.7014 & 13.516 \\
CONS & 1945 & 2.5205 & 6.8899 & 1.2077 & 0.7664 & 1.0578 & 4.6793 \\
ELCT & 1945 & 3.0584 & 14.057 & 0.4861 & 1.8201 & 1.9482 & 8.3707 \\
HLTH & 1945 & 1.3734 & 0.0224 & 0.0000 & 1.9880 & 2.4941 & 9.8792 \\
KSEX & 1945 & 1.3417 & 9.3528 & 0.7896 & 0.8211 & 2.1721 & 16.777 \\
OGEX & 1945 & 1.4896 & 6.8293 & 0.0000 & 0.7137 & 1.5271 & 9.9462 \\
TRVL & 1945 & 1.2454 & 6.1714 & 0.0000 & 1.0080 & 1.3996 & 5.7953 \\
\hline
\end{tabular}

Source: Author's own calculations 